\title{
Effect of an isotonic rehydration sports drink and exercise on urolithiasis in rats
}

\section{N.P. Abreu ${ }^{1}$, \\ C.T. Bergamaschi ${ }^{2}$, \\ G.S. di Marco ${ }^{1}$, \\ C.V. Razvickas ${ }^{1}$, and N. Schor ${ }^{1}$}

\author{
${ }^{1}$ Disciplina de Nefrologia, Departamento de Medicina, \\ ${ }^{2}$ Disciplina de Fisiologia Cardiovascular e Respiratória, \\ Departamento de Farmacologia, \\ Universidade Federal de São Paulo, São Paulo, SP, Brasil
}

\section{Correspondence \\ N. Schor \\ Divisão de Nefrologia \\ Departamento de Medicina \\ EPM, UNIFESP \\ Rua Botucatu, 740 \\ 04023-900 São Paulo, SP \\ Brasil \\ E-mail: nestor@nefro.epm.br \\ Research supported by CAPES, CNPq, FAPESP, and Fundação Oswaldo \\ Ramos.}

Received June 24, 2004

Accepted February 10, 2005

\begin{abstract}
The objective of the present study was to evaluate the role of physical exercise as well as the influence of hydration with an isotonic sports drink on renal function in male Wistar rats. Four groups were studied over a period of 42 days: 1) control $(\mathrm{N}=9) ; 2$ ) physical exercise (Exe, $\mathrm{N}=7$ ); 3) isotonic drink (Drink, $\mathrm{N}=8$ ); 4) physical exercise + isotonic drink (Exe + Drink, $\mathrm{N}=8$ ). Physical exercise consisted of running on a motor-driven treadmill for $1 \mathrm{~h} /$ day, at $20 \mathrm{~m} / \mathrm{min}, 5$ days a week. The isotonic sports drink was a commercial solution used by athletes for rehydration after physical activity, $2 \mathrm{ml}$ administered by gavage twice a day. Urine cultures were performed in all animals. Twenty-four-hour urine samples were collected in metabolic cages at the beginning and at the end of the protocol period. Urinary and plasma parameters (sodium, potassium, urea, creatinine, calcium) did not differ among groups. However, an amorphous material was observed in the bladders of animals in the Exe + Drink and Drink groups. Characterization of the material by Western blot revealed the presence of Tamm-Horsfall protein and angiotensin converting enzyme. Physical exercise and the isotonic drink did not change the plasma or urinary parameters measured. However, the isotonic drink induced the formation of intravesical matrix, suggesting a potential lithogenic risk.
\end{abstract}

\section{Introduction}

Sports drinks have been developed primarily for use during or after exercise, and in general contain carbohydrate and low concentrations of electrolytes, usually sodium and potassium (1). Preservation of hydration remains the most important goal during exer-
Key words

- Renal function

- Isotonic rehydration sports drink

- Physical activity

- Renal stone

- Nephrolithiasis

- Tamm-Horsfall protein 
tain hydration. This advice should be even stronger if patients practice physical activity (2). Urolithiasis is a sequence of complex physical processes that involve saturation, supersaturation, nucleation, aggregation, and stones formation (3). It can originate mainly from low urinary volumes, hypercalciuria, hyperuricosuria, hyperoxaluria, hypocitraturia, and hypomagnesiuria, and also from urinary infection (4). In addition, acute renal colic can be induced by exercises, dehydration and reduction of urinary volume. Other factors such as increased protein ingestion and administration of some medicines have also been reported (5).

An increase in the concentration of large diameter particles has been observed in the urine of marathon athletes, possibly increasing crystalluria and the risk of nephrolithiasis (6). A controversial question, however, is what can reduce urolithiasis induced by physical exercise. Two major views have been recently proposed. The first is that the risk of urolithiasis can be reduced by increased liquid intake $(7,8)$. The second is that the amount of electrolytes (and glucose) added to drinking water leads to a more complete rehydration than the ingestion of just water.

The objective of the present study was to determine if the use of a commercial sports drink associated or not with exercise represents a potential risk for renal stones or possible inducive factors.

\section{Material and Methods}

Experiments were performed on male Wistar rats provided by the Central Animal House of the Federal University of São Paulo. All animal procedures were conducted according to the "Guidelines for ethical care of experimental animals from the UNIFESPEPM" and were approved by the Institutional Ethics Committee, Process No. 776/ 01 .

Animals were divided into four groups:
1) control $(\mathrm{N}=9)$; 2) physical exercise (Exe, $\mathrm{N}=7$ ); 3) sports drink (Drink, $\mathrm{N}=8$ ); 4) physical exercise + sports drink (Exe + Drink, $\mathrm{N}=8$ ).

\section{Physical exercise}

Animals from the Exe and Exe + Drink groups were submitted to running on a motor-driven treadmill for $1 \mathrm{~h} /$ day, at $20 \mathrm{~m} / \mathrm{min}$, 5 days a week (Columbus Instruments ${ }^{\circledR}$, Columbus, OH, USA). This level corresponds to moderate intensity $(9,10)$.

\section{Isotonic sports drink}

Groups Drink and Exe + Drink received by gavage a commercial isotonic sports drink used by athletes for rehydration after physical activity, $2 \mathrm{ml}$ twice a day. As described by the manufacturer, the content of $100 \mathrm{ml}$ of this solution is: $24 \mathrm{kcal}$ energy, $6.0 \mathrm{~g}$ carbohydrate, $0.0 \mathrm{~g}$ protein, $0.0 \mathrm{~g}$ lipids, $45.0 \mathrm{mg}$ sodium, $12.0 \mathrm{mg}$ potassium, $42.0 \mathrm{mg}$ chloride, and $0.0 \mathrm{mg}$ dietary fiber.

\section{Biochemical parameters}

For urine collection, rats were placed in metabolic cages for $24 \mathrm{~h}$ at the beginning and at the end of the 42-day period of the protocol. Urinary parameters analyzed were sodium, potassium, calcium, urea, creatinine, oxalate, citrate, and total urinary volume. Plasma was collected only at the end of the protocol period for the determination of sodium, potassium, calcium, magnesium, urea, and creatinine. To be certain that urine was not contaminated with bacteria, urine samples were collected from all animals under aseptic conditions and cultured. For the evaluation of renal function, creatinine clearance was calculated using the formula UV/P, were $\mathrm{U}$ is the creatinine concentration in urine, $\mathrm{V}$ is the 24-h urinary volume, and $\mathrm{P}$ is the plasma creatinine concentration. The sodium and potassium excretion rate was also calcu- 
lated. The final samples were collected at least $24 \mathrm{~h}$ after the last exercise session. The animals were then sacrificed with an overdose of anesthesia.

\section{Histology}

At the end of the study period, the kidneys of all animals were removed and fragments were stained with hematoxylin and eosin for morphological evaluation. The bladders were opened for examination and any content was removed for evaluation.

\section{Western blotting}

The amorphous matrix found in the bladder of animals from groups Drink $(\mathrm{N}=8)$ and Exe + Drink $(\mathrm{N}=8)$ was analyzed by $7.5 \%$ sodium dodecyl sulfate-polyacrylamide gel electrophoresis (SDS-PAGE) performed by the method of Laemmli (11) under reducing conditions. The proteins separated by SDS-PAGE $(100 \mu \mathrm{g})$ were submitted to Western blotting analysis using a nitrocellulose membrane. Both membranes were blocked with 5\% non-fat milk (Molico, Nestlé, São Paulo, SP, Brazil) in TBST (20 $\mathrm{mM}$ Tris, $500 \mathrm{mM} \mathrm{NaCl}, 500 \mu \mathrm{g}$ Tween, $\mathrm{pH}$ $7.5)$ for $6 \mathrm{~h}$. The membranes were washed twice with TBST (10 min each time) and incubated with mouse anti-Tamm-Horsfall protein (THP) and mouse anti-angiotensin converting enzyme (ACE) monoclonal and/ or polyclonal antibodies $(1: 250,1 \%$ albumin in TBS; Sigma, St. Louis, MO, USA) for $8 \mathrm{~h}$. The antibody bound to the enzyme was detected by the secondary anti-mouse IgGbiotin conjugate $(1: 1000,1 \%$ albumin in TBS) for $1 \mathrm{~h}$. The membranes were incubated with streptavidin/alkaline phosphatase (1:3000, 1\% albumin in TBS) for $30 \mathrm{~min}$. The washing step was repeated between incubations. The protein bands were finally developed using the BCIP/NBT substrates, as recommended by the manufacturer (BioRad Laboratories, Inc., Hercules, CA, USA).

\section{Statistical analysis}

Data are reported as means \pm SEM. The results were analyzed statistically by the Student $t$-test, one-way ANOVA and the chisquare test when appropriate, with the level of significance set at $\mathrm{P}<0.05$.

\section{Results}

Urine values are presented as pre- and post-treatment, while the plasma parameters were determined only at the end of the experimental protocol.

Exercise or sports drink, or both, did not produce any change in the plasma parameters (Table 1). The Exe + Drink group presented a smaller increase in body weight (16 $\pm 1.8 \mathrm{~g})$ compared to control $(32 \pm 2.1 \mathrm{~g}, \mathrm{P}<$ $0.05)$. There were no significant variations in the values of urinary potassium, urea, creatinine, oxalate, citrate, or calcium obtained before and after treatment in any group (Table 1). Urinary sodium excretion decreased after treatment in the Drink group (from $1.1 \pm 0.1$ to $0.7 \pm 1 \mathrm{mEq} / 24 \mathrm{~h}, \mathrm{P}<$ $0.05)$. However, the value obtained after treatment did not differ from other groups. Fractional sodium and potassium excretion did not differ between groups or before and after treatment. We also observed that urinary volume differed between the pretreatment $(8 \pm 0.4 \mathrm{ml})$ and post-treatment $(14 \pm$ $1.6 \mathrm{ml}$ ) period only in the Exe group (Table $1)$.

A gelatinous amorphous protein matrix was found in the bladder of 5 of 12 animals $(41.6 \%)$ in the Drink group and in 1 of 8 animals $(12.5 \%)$ in the Exe + Drink group. There was no evidence of infectious or inflammatory processes or of the presence of fungus. No crystalloid material was detected. In addition, urine culture did not indicate the presence of bacteria. SDS-PAGE revealed the presence of proteins of different molecular weights around 90 and $70 \mathrm{kDa}$. Western blotting detected THP and ACE after elec- 


\begin{tabular}{|c|c|c|c|c|}
\hline & Control & Exercise & Drink & Exercise + Drink \\
\hline \multicolumn{5}{|l|}{ Plasma values } \\
\hline $\mathrm{Na}^{+}(\mathrm{mEq} / \mathrm{l})$ & $143 \pm 6.3$ & $157 \pm 3.4$ & $143 \pm 2.5$ & $147 \pm 3.6$ \\
\hline $\mathrm{K}^{+}(\mathrm{mEq} / \mathrm{l})$ & $4.5 \pm 0.3$ & $5.6 \pm 0.2$ & $4.6 \pm 0.2$ & $4.8 \pm 0.1$ \\
\hline $\mathrm{Ca}^{2}+(\mathrm{mg} / \mathrm{dl})$ & $9.0 \pm 1.0$ & $9.0 \pm 0.3$ & $9.7 \pm 0.1$ & $10.2 \pm 0.2$ \\
\hline $\mathrm{Mg}^{2+}(\mathrm{mg} / \mathrm{dl})$ & $2.2 \pm 0.07$ & $2.5 \pm 0.09$ & $2.0 \pm 0.1$ & $2.4 \pm 0.08$ \\
\hline Urea (mg/dl) & $43 \pm 1.1$ & $50 \pm 3.8$ & $53 \pm 2.6$ & $46 \pm 2.6$ \\
\hline Creatinine (mg/dl) & $0.9 \pm 0.03$ & $0.8 \pm 0.07$ & $1.0 \pm 0.3$ & $1.0 \pm 0.09$ \\
\hline Creatine clearance (ml/min) & $1.1 \pm 0.1$ & $0.9 \pm 0.08$ & $0.8 \pm 0.09$ & $0.7 \pm 0.04$ \\
\hline \multicolumn{5}{|l|}{ Weight } \\
\hline Before (g) & $234 \pm 6.0$ & $212 \pm 2.6$ & $229 \pm 11.0$ & $241 \pm 9.0$ \\
\hline After (g) & $346 \pm 5^{a}$ & $283 \pm 12^{a}$ & $308 \pm 14$ & $288 \pm 10^{a}$ \\
\hline$\Delta \%$ & $32.0 \pm 2.1^{b}$ & $24.0 \pm 3.0$ & $25.0 \pm 1.7$ & $16.0 \pm 1.8^{b}$ \\
\hline \multicolumn{5}{|l|}{ Urinary values } \\
\hline \multicolumn{5}{|l|}{$\mathrm{Na}^{+}(\mathrm{mEq} / 24 \mathrm{~h})$} \\
\hline Before & $0.8 \pm 0.05$ & $0.9 \pm 0.06$ & $1.1 \pm 0.1$ & $1.0 \pm 0.2$ \\
\hline After & $0.7 \pm 0.1$ & $1.0 \pm 0.08$ & $0.7 \pm 0.09 c$ & $0.8 \pm 0.1$ \\
\hline \multicolumn{5}{|l|}{$\mathrm{K}^{+}(\mathrm{mEq} / 24 \mathrm{~h})$} \\
\hline Before & $1.5 \pm 0.08$ & $1.7 \pm 0.1$ & $1.8 \pm 0.4$ & $1.8 \pm 0.2$ \\
\hline After & $1.2 \pm 0.1$ & $1.5 \pm 0.1$ & $1.1 \pm 0.1$ & $1.3 \pm 0.1$ \\
\hline \multicolumn{5}{|l|}{ Urea (mg/24 h) } \\
\hline Before & $378 \pm 19$ & $366 \pm 15$ & $429 \pm 38$ & $393 \pm 63$ \\
\hline After & $334 \pm 24$ & $392 \pm 22$ & $417 \pm 38$ & $385 \pm 21$ \\
\hline \multicolumn{5}{|l|}{ Creatinine (mg/24 h) } \\
\hline Before & $9.5 \pm 0.7$ & $8.6 \pm 0.7$ & $10.4 \pm 1.1$ & $10.0 \pm 2.0$ \\
\hline After & $10.2 \pm 0.5$ & $9.1 \pm 0.7$ & $10.3 \pm 0.9$ & $10.5 \pm 0.7$ \\
\hline \multicolumn{5}{|l|}{ Oxalate (mg/24 h) } \\
\hline Before & $0.5 \pm 0.04$ & $0.5 \pm 0.06$ & $0.6 \pm 0.05$ & $0.7 \pm 0.09$ \\
\hline After & $0.4 \pm 0.04$ & $0.5 \pm 0.1$ & $0.5 \pm 0.05$ & $0.6 \pm 0.05$ \\
\hline \multicolumn{5}{|l|}{ Citrate (mg/24 h) } \\
\hline Before & $25.9 \pm 1.7$ & $26.9 \pm 1.7$ & $24.6 \pm 3.0$ & $26.0 \pm 5.0$ \\
\hline After & $23.5 \pm 3.5$ & $23.9 \pm 1.9$ & $20.9 \pm 2.6$ & $20.0 \pm 2.0$ \\
\hline \multicolumn{5}{|l|}{ Calcium (mg/24 h) } \\
\hline Before & $0.4 \pm 0.03$ & $0.4 \pm 0.3$ & $0.4 \pm 0.1$ & $0.3 \pm 0.04$ \\
\hline After & $0.4 \pm 0.05$ & $0.4 \pm 0.05$ & $0.5 \pm 0.1$ & $0.4 \pm 0.05$ \\
\hline \multicolumn{5}{|l|}{ Total urinary volume (ml) } \\
\hline Before & $11 \pm 0.8$ & $8 \pm 0.4$ & $10 \pm 1.0$ & $12 \pm 2.0$ \\
\hline After & $10 \pm 1.2$ & $14 \pm 1.6^{c}$ & $12 \pm 1.3$ & $12 \pm 1.8$ \\
\hline
\end{tabular}

Data are reported as means \pm SEM.

ap $<0.05$ for Control vs Exercise vs Exercise + Drink; bP $<0.05$ for Control vs Exercise + Drink (ANOVA); ${ }^{c P}$ $<0.05$ before vs after treatment ( $t$-test).

trophoresis and transfer.

Histological evaluation confirmed the absence of morphological alterations in the glomeruli and tubular or interstitial kidney structures as well as no crystal precipitates.

\section{Discussion}

The main finding of the present study was that an isotonic sports drink promotes the formation of an amorphous substance in Wistar rat bladder, which suggests a lithogenic risk in the present experimental protocol. No alterations in plasma or urinary biochemical parameters were observed which could explain this result. The first hypothesis was that an increase in sodium intake with the sports drinks was responsible for 
the formation of the vesical substance. Increased sodium intake may promote a variety of metabolic changes that may be detrimental to stone forming patients, including increases in $\mathrm{pH}$, calcium, and cystine excretion and a decrease in citrate excretion (12). However, in this study, no significant difference was found in plasma or urinary sodium concentration (Table 1), suggesting that the formation observed in response to the isotonic sports drink was not dependent on sodium.

The only significant difference was found in urinary sodium concentration in the sports drink group between pre- and post-treatment. Despite the presence of calcium in the amorphous intravesical material, no alteration in plasma or urinary calcium concentration was found in the sports drink or Exe + Drink groups. Magnesium and citrate, both considered to protect against lithogenesis, remained stable in all groups. The level of oxalate, considered a stone promoter, also remained at normal levels in all groups.

No changes in urea or creatinine levels were observed, suggesting the maintenance of renal function in all animals. The weight of the animals varied as expected. The animals in group Exe + Drink showed a smaller weight increase compared to control. This variation was probably due to the effect of aerobic physical activity on weight gain, increasing calorie expenditure. No reduction of 24-h urinary volume was observed in any group (Table 1). These results suggest that the intensity of physical exercise was moderate and was not able to produce longterm dehydration. We should point out that urine was collected at least $24 \mathrm{~h}$ after the last exercise or drinking session, thus excluding possible acute effects. The Exe group presented a significant variation in urinary volume before and after treatment. However, urinary volume increased after treatment and the final volume was not different from those found in the other groups.

Some types of bacteria can provoke uri- nary supersaturation and modify the environment, thus leading to the formation of crystal deposits (13) that may be a factor promoting urolithiasis. However, the results of urinary culture ruled out the presence of any infection.

A substance in gelatinous form was detected in the bladder of 1 of 8 animals of the Exe + Drink group (12.5\%) and in 5 of 12 animals (41.6\%) of the Drink group but not in control animals. Histological analysis of this substance suggested an amorphous protein matrix. Calculogenic matrices are mechanisms that allow heterogeneous nucleation as the main factor in stone formation (14). Protein, which is a major component of the urinary stone matrix, interacts with crystals and can modulate crystallization effectively in a positive or negative fashion. Based on its identification and isolation from human stones, it was suggested that THP, the most abundant protein in normal human urine, might have a role in stone formation (15).

THP and ACE formed the protein matrix detected in these Wistar rats. Other studies have also demonstrated that THP, when precipitated in the bladder in gel form, leads to aggregation of other compounds (14), a fact that could explain the simultaneous presence of ACE. Since THP has a tendency to form a gel in the urinary tract $(14,16)$, it may have a possible lithogenic risk. The role of THP in stone formation is still controversial. In several studies urinary THP excretion in stone forming patients was lower than in normal subjects $(17,18)$. In contrast, other studies have shown that average excretion was similar in the various groups studied $(19,20)$. Furthermore, the effects of THP on crystal aggregation can be significantly modified by factors such as THP concentration and the presence or absence of citrate and other ions in the environment. This could be an explanation for the presence of THP in rats receiving the sports drink since this drink contains different known substances which 
could modify urine concentration.

The main question that can be raised is: what promotes gel formation? Urinary dilution has been found to increase the inhibitory activity of THP on calcium oxalate monohydrate crystal aggregation in the urine of stone formers (12). It has been demonstrated that an increase in salt intake facilitates THP production (21), thus promoting renal stone formation $(22,23)$. The increase in fluid consumption results in excretion of a higher volume of urine, which is less supersaturated and theoretically reduces stone formation. However, these beneficial effects appear to be related to the drink choice. In a case-control study, Shuster et al. (24) demonstrated a strong correlation between consumption of soft drinks and de- velopment of nephrolithiasis in man. This effect was detected in individuals whose most consumed soft drink was acidified with phosphoric acid but not with citric acid (24). Other studies have demonstrated a positive association between kidney stone development and intake of apple and grapefruit juice. The mechanism involved is still unclear at this time (25).

Our results indicate that the use of an isotonic sports drink induces precipitation of THP in the urine and the formation of a bladder protein matrix in Wistar rats. It would be premature to extrapolate the results on Wistar rats to man. Experiments with people are required to determine if isotonic sports drinks present this problem in healthy subjects or nephrolithiasic patients.

\section{References}

1. Burke LM \& Read RS (1993). Dietary supplements in sport. Sports Medicine, 15: 43-65.

2. Colussi G, Ferrari ME, Brunati C \& Civati G (2000). Medical prevention and treatment of urinary stones. Journal of Nephrology, 13 (Suppl 3): S65-S70.

3. Balaji KC \& Menon M (1997). Mechanism of stone formation. Urologic Clinics of North America, 24: 1-11.

4. Hruska K, Seltzer J \& Grieff M (1997). Nephrolithiasis. In: Schirier RW \& Gottschalk CW (Editors), Diseases of the Kidney. 6th edn. Vol. I. Little Brown and Company, Boston, MA, USA, 739-764.

5. Bihl G \& Meyers A (2001). Recurrent renal stone disease - advances in pathogenesis and clinical management. Lancet, 25: 651-656.

6. Rodgers A, Greyling K \& Noakes T (1991). Crystalluria in marathon runners. Urological Research, 19: 189-192.

7. Pak CY, Smith LH, Reisnick MI \& Weinerth JL (1984). Dietary management of idiopathic calcium urolithiasis. Journal of Urology, 131: 850-852.

8. Vahlensieck W (1986). The importance of diet in urinary stones. Urological Research, 14: 283-288.

9. Brooks G \& White T (1978). Determination of metabolic and heart rate responses of rats to treadmill exercise. Journal of Applied Physiology, 45: 1009-1015.

10. Veras-Silva AS, Mattos KC, Gava NS, Brum PC, Negrão CE \& Krieger EM (1997). Low-intensity exercise training decreases cardiac output and hypertension in spontaneously hypertensive rats. American Journal of Physiology, 273: H2627-H2631.

11. Laemmli UK (1970). Cleavage of structural proteins during the assembly of the head of bacteriophage T4. Nature, 227: 680-685.

12. Assimos DG \& Holmes RP (2000). Role of diet in the therapy of urolithiasis. Urological Clinics of North America, 27: 255-268.

13. Asplin J, Favus M \& Coe F (2000). Nephrolithiasis. In: Brenner BM \& Rector FC (Editors), The Kidney. Saunders, Philadelphia, PA, USA, 1774-1819.

14. Schor N \& Heilberg I (1995). Fisiologia dos inibidores e agregadores da litogênese. In: Calculose Renal: Fisiopatologia, Diagnóstico, Tratamento. Sarvier, São Paulo, SP, Brazil.

15. Gokhale J, McKee M \& Khan S (1996). Immunocytochemical localization of Tamm-Horsfall protein in the kidney of normal and nephrolithic rats. Urological Research, 24: 201-209.

16. Pressac M (2000). Tamm-Horsfall protein. Annales de Biologie Clinique, 58: 167-176.

17. Bichler KH, Kirchner CH \& Ideler V (1975). Uromucoid excretion of normal individuals and stone formers. British Journal of Urology, 47: 733-737.

18. Hess B (1994). Tamm Horsfall glycoprotein and calcium nephrolithiasis. Mineral and Electrolyte Metabolism, 20: 393-398.

19. Lynn KL, Shenkin A \& Marshall RD (1982). Factors affecting excretion of human urinary Tamm Horsfall glycoprotein. Clinical Science, 62: $21-26$

20. Thornely C, Dawnay A \& Cattell WR (1985). Human Tamm Horsfall glycoprotein: urinary and plasma levels in normal subjects and patients with renal disease determined by a fully validated radioimmunoassay. Clinical Science, 68: 529-535.

21. Yinng $W \&$ Sanders $P(1998)$. Dietary salt regulates expression of Tamm-Horsfall glycoprotein in rats. Kidney International, 54: 11501156.

22. Cirillo $M$, Laurenzi $M$, Panarelli W \& Stamler J (1994). Urinary sodium to potassium ratio and urinary stone disease. Kidney International, 46: 1133-1139.

23. Stamler J \& Cirillo M (1997). Dietary salt and renal stone disease. Lancet, 349: 506-507.

24. Shuster J, Jenkins A, Logan C, Barnett $T$, Rihele R \& Zackson D (1992). Soft drink consumption and urinary stone recurrence: a randomized prevention trial. Journal of Clinical Epidemiology, 45: 911-916.

25. Curham GC, Willett WC, Rimm EB, Spiegelmen D \& Stampfer MJ (1996). Prospective study of beverage use and the risk of kidney stones. American Journal of Epidemiology, 143: 240-247. 